\title{
The synergism of $\mathrm{MgCO}_{3}$ and $2 \mathrm{ZnCO}_{3} \cdot 3 \mathrm{ZnO} \cdot 4 \mathrm{H}_{2} \mathrm{O}$ as flame retardants and smoke suppressants for flexible poly(vinyl chloride) (PVC)
}

Hongqiang Qu, ${ }^{1 *}$ Weihong Wu, ${ }^{12}$ Yunhong Jiao, ${ }^{1}$ Jixing Xie, ${ }^{1}$ Jianzhong $X u^{1}$

1 College of Chemistry and Environmental Science, Hebei University, Baoding, 071002, China; fax: 86-0312-5079795, e-mail: hqqu@163.com

${ }^{2}$ College of Science, Agriculture University of Hebei, Baoding, 071001, China; fax: 86-0312-5079795, e-mail: weiweibigq@163.com

(Received: 12 November, 2010; published: 17 August, 2011)

\begin{abstract}
MgCO}_{3}$ and $2 \mathrm{ZnCO}_{3} \cdot 3 \mathrm{ZnO} \cdot 4 \mathrm{H}_{2} \mathrm{O}$ (AZC) as flame-retardants and smoke suppressants for flexible poly(vinyl chloride) (PVC) was evaluated using limiting oxygen index (LOI), smoke density rating (SDR) tests, scanning electron microscopy (SEM) and thermogravimetry analysis (TGA). The activation energy $\left(E_{\mathrm{a}}\right)$ of the original and flame retardant PVCs' degradation processes was calculated by the Vyazovkin method. The results showed that the AZC can be used as a synergistic agent for $\mathrm{MgCO}_{3}$ as flame retardants agent of flexible PVC. The composites of $\mathrm{MgCO}_{3}$ and $\mathrm{AZC}$ cannot only decrease the initial decomposition temperature and increase the weight loss rate in the first stage, but also can promote the char formation in the second stage. The AZC decreased the $E_{\mathrm{a}}$ of the degradation reaction of $\mathrm{PVC}$ in the first stage and $\mathrm{MgCO}_{3}$ increased the $E_{\mathrm{a}}$ in the second stage, which means that the AZC combined with $\mathrm{MgCO}_{3}$, catalyzed the dehydrochlorination, promoted the early crosslinking for the PVC compound and improve the stability of the char residue. The SEM results also show that the char residue of $\mathrm{MgCO}_{3} / \mathrm{AZC}$ treated sample has a continuous and denser structure, which can be used as a barrier for the PVC bulk.
\end{abstract}

\section{Introduction}

PVC, a commodity thermoplastic, has been widely used in various aspects, such as wire and cable, building materials, upholstery, etc. PVC is an inherently flame retardant polymer with some additives, especially plasticizers such as di(2-ethylhexyl) phthalate (DOP) which can make PVC flexible and less resistant to ignition unless flame retardants and smoke suppressant additives are incorporated. Compound additives containing metals like antimony, zinc, copper, iron, aluminium, magnesium, and molybdenum are widely used in reducing flammability and in smoke suppression, in which the most important commercial smoke suppressants are zinc, magnesium and aluminum compounds, such as zinc borate $\left(\mathrm{XZnO} \cdot \mathrm{YB}_{2} \mathrm{O}_{3} \cdot \mathrm{ZH}_{2} \mathrm{O}\right), \mathrm{Al}(\mathrm{OH})_{3}$, $\mathrm{Mg}(\mathrm{OH})_{2}$ and $\mathrm{MgCO}_{3}$ etc. are commonly used [1-6]. Although these fillers are essentially non-toxic and relatively inexpensive, the high volume of addition for excellent flame retardancy often leads to processing difficulties and a marked deterioration in other critical polymer characteristics, including mechanical, physical and electrical properties [7-8]. Using coupling agents and synergists are good ways to solving these problems. The previous work showed that some synergistic flameretardants such as zinc borate [3], tin additives [9], metal chelates [10-11] and some other metal oxides [12-13] can enhance the effectiveness of $\mathrm{Al}(\mathrm{OH})_{3}$ or $\mathrm{Mg}(\mathrm{OH})_{2}$ and then decrease the loading level as flame retardant and smoke suppression for PVC. 
However, the synergism of $\mathrm{MgCO}_{3}$ and AZC as flame retardants and smoke suppressant for flexible PVC has not been reported yet. What's more, compared with $\mathrm{ZnCO}_{3}$ (the decomposition temperature is $350^{\circ} \mathrm{C}$ ), the decomposition temperature of AZC is $220^{\circ} \mathrm{C}$, which is more corresponding to that of PVC. Moreover, there is much water vapour released when AZC is decomposed, which is beneficial to the improvement of flame retardancy.

In this article, the synergism of $\mathrm{MgCO}_{3}$ and $\mathrm{AZC}$ as flame-retardants and smoke suppressants for flexible PVC were evaluated by the LOI and SDR tests. The thermal decomposition behavior and the mechanism of the PVC sample were studied by the TGA and the SEM. The $E_{\mathrm{a}}$ was also calculated by the Vyazovkin method.

\section{Results and discussion}

\section{Flame-retardant and smoke suppressant}

As shown in Table 1, the LOI value of the untreated PVC sample is $25.3 \%$, after treated with the $20 \mathrm{phr} \mathrm{MgCO}_{3}$ or $\mathrm{AZC}$, the value increased to $28.4 \%$ and $28.0 \%$, respectively. When the ratio $(\mathrm{w} / \mathrm{w})$ of $\mathrm{MgCO}_{3}$ and AZC is $10: 1$, the flexible PVC (sample I) has the best flame retardancy, and the LOI of the PVC sample increases from 25.3 to $29.9 \%$. The results indicate an obviously synergism of $\mathrm{MgCO}_{3}$ and AZC. Similar results are obtained in the SDR and the MSD experiment, when the ratio $(\mathrm{w} / \mathrm{w})$ of $\mathrm{MgCO}_{3}$ and $\mathrm{AZC}$ is $2: 1$, the flexible PVC has the best smoke suppression; the SDR of the PVC sample was decreased from 86.9 to $68.3 \%$ and the MSD was decreased from 100.0 to $92.6 \%$. Compared with the previous work [3, 9-12], the AZC can also obviously increase the effectiveness of $\mathrm{MgCO}_{3}$ as flame retardants and smoke suppression for flexible PVC.

Tab. 1. Flame retardant and smoke suppressant properties of PVC samples.

\begin{tabular}{cccccc}
\hline sample & Flame retardants & $\begin{array}{c}\text { Content } \\
{[\text { phr] }}\end{array}$ & LOI [\%] & $\begin{array}{c}\text { SDR } \\
{[\%]}\end{array}$ & $\begin{array}{c}\text { MSD } \\
{[\%]}\end{array}$ \\
\hline $\mathrm{A}$ & -- & 0 & 25.3 & 86.9 & 100.0 \\
$\mathrm{~B}$ & $\mathrm{MgCO}_{3}$ & 20 & 28.4 & 77.8 & 100.0 \\
$\mathrm{C}$ & $\mathrm{AZC}$ & 20 & 28.0 & 90.2 & 100.0 \\
$\mathrm{D}$ & $\mathrm{MgCO}_{3}: \mathrm{AZC}=1: 1(\mathrm{w} / \mathrm{w})$ & 20 & 28.2 & 84.0 & 100.0 \\
$\mathrm{E}$ & $\mathrm{MgCO}_{3}: \mathrm{AZC}=1: 5(\mathrm{w} / \mathrm{w})$ & 20 & 28.3 & 81.7 & 100.0 \\
$\mathrm{~F}$ & $\mathrm{MgCO}_{3}: \mathrm{AZC}=1: 2(\mathrm{w} / \mathrm{w})$ & 20 & 28.3 & 85.3 & 100.0 \\
$\mathrm{G}$ & $\mathrm{MgCO}_{3}: \mathrm{AZC}=2: 1(\mathrm{w} / \mathrm{w})$ & 20 & 28.5 & 68.3 & 92.6 \\
$\mathrm{H}$ & $\mathrm{MgCO}_{3}: \mathrm{AZC}=5: 1(\mathrm{w} / \mathrm{w})$ & 20 & 29.7 & 81.7 & 100.0 \\
$\mathrm{I}$ & $\mathrm{MgCO}_{3}: \mathrm{AZC}=10: 1(\mathrm{w} / \mathrm{w})$ & 20 & 29.9 & 83.7 & 100.0 \\
\hline
\end{tabular}

Note: the basic recipe of the sample is: PVC $100 \mathrm{phr}$, DOP $40 \mathrm{phr}$, stabilizer $3 \mathrm{phr}$, calcium stearate 1 phr, coupling agent $1 \mathrm{phr}$, and flame retardants $20 \mathrm{phr}$.

\section{Thermal analysis}

The thermal decomposition behavior is a very important factor for studying the flame retardant behavior of materials. It plays a very important role in heat release and weight loss behavior during burning, which are not obtained from the LOI and SDR test. The thermal degradation of $\mathrm{PVC}, \mathrm{MgCO}_{3}$ and $\mathrm{AZC}$ as well as that of their mixtures were studied in order to understand their effect on the combustion behavior of flexible PVC with particular reference to $\mathrm{MgCO}_{3}$ and $\mathrm{AZC}$ synergism. 
As shown in Figure $1(\mathrm{a}-\mathrm{d})$ and Table 2, the decomposition on thermogravimetry (TG) curves can be divided into two stages. The first stage from 240 to $350{ }^{\circ} \mathrm{C}$ is mainly due to the emission of hydrogen chloride and the degradation of DOP [14, 15]. All the samples' weight loss is about $50-67 \mathrm{wt} \%$ at the first stage. In fact, for the untreated PVC sample, just over $65 \mathrm{wt} \%$ is lost.
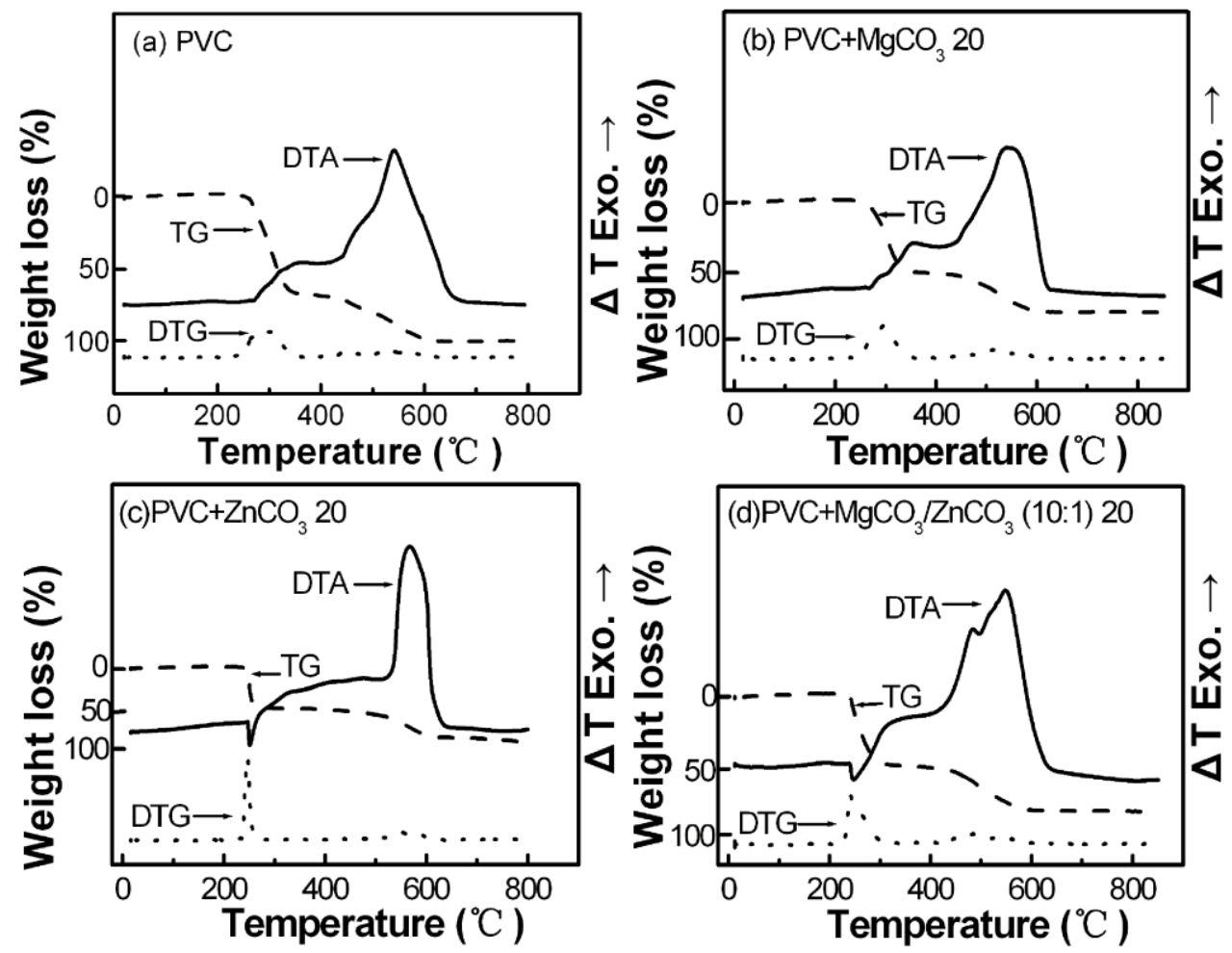

Fig. 1. TG-DTG-DTA curves of PVC samples (a-d). (Samples were heated at a rate of $20{ }^{\circ} \mathrm{C} \mathrm{min}{ }^{-1}$ under air with a flow rate of $\left.60 \mathrm{ml} \mathrm{min}^{-1}\right)$.

The weight loss of the first stage is obviously decreased by the contribution of the flame retardants. The temperature range and the temperature at the maximum rate of weight loss (TM) of the $\mathrm{MgCO}_{3}$-treated sample (sample $\mathrm{B}$, Figure $1(\mathrm{~b})$ ) are very similar with the untreated PVC (sample A, Figure 1(a)), while the initial decomposition temperature and the maximum rate of weight loss (MV) are slightly increased. The reason is that the $\mathrm{MgCO}_{3}$ cannot decompose until the temperature exceeds $500{ }^{\circ} \mathrm{C}$ (as shown in Figure 2 (a)). While the initial decomposition temperature, the final decomposition temperature and the TM of the AZC-treated sample are decreased obviously, especially the final decomposition temperature decreased from 350 to 275 ${ }^{\circ} \mathrm{C}$. The temperature range of the $\mathrm{AZC}$-treated sample is more narrowed than the untreated sample, and the MV is increased clearly. These results can be explain with the assumption of that $A Z C$ can absorb heat during the decomposition from 210 to $300{ }^{\circ} \mathrm{C}$ (as shown in Figure $2(\mathrm{~b})$ ) and form $\mathrm{ZnO}, \mathrm{H}_{2} \mathrm{O}$ and $\mathrm{CO}_{2}$, and then $\mathrm{ZnO}$ reacts with $\mathrm{HCl}$ to form $\mathrm{ZnCl}_{2}$, which is a kind of stronger Lewis acid that can catalyze the dehydrochlorination and promote the early crosslinking to the PVC compound [16]. The $\mathrm{HCl}$ released is an effective gas-phase flame inhibitor and such a carbonized product is believed to protect the polymer backbone, inhibit heat and $\mathrm{O}_{2}$ degradation during combustion and hence contribute to the flame retardancy. In sample I (Figure 1 (d)), although the content of AZC is very small, it can still decrease the initial 
decomposition temperature and the TM of the sample, and the MV also increased from 2.09 to $2.32 \mathrm{mg} \cdot \mathrm{min}^{-1}$.

The second stage is where the carbonaceous backbone suffers chain scission and thus lowers molecular weight compounds (and smoke) are produced and the unstable char is oxidized [14]. The temperature range and the initial decomposition temperature in the second stage of the sample treated with $\mathrm{MgCO}_{3}$ (sample $\mathrm{B}$, Figure $1(b)$ ) are at the same level with the untreated PVC (sample A, Figure 1(a)), but the weight loss decreased, which mean that there will be more residues generated after the second stage. For the AZC-treated sample, the weight loss increased form 29.2 to $34.3 \%$, and both the MV and TM in the second stage increased, even after $700{ }^{\circ} \mathrm{C}$ the weight loss is still significant, indicating that the AZC will promote the degradation reactions of the char residue at a higher temperature. Since the $\mathrm{ZnO}$ does not vaporize below $1000{ }^{\circ} \mathrm{C}$, the presence of reducing gases (pyrolysis and combustion products) could provide a lower temperature volatilization route. In this route, free zinc metal would be an intermediate phase, and zinc oxide aerosols would be counted by the photometer as smoke [17], so with the AZC at higher levels in the PVC samples would adversely affect the flame retardancy and smoke suppression of the samples. These results may be able to explain the reason of why the SDR of the samples decreased from $83.7 \%$ to $68.3 \%$ with the increase of the content of $A Z C$ and then increased with the lowest value of $\mathrm{SDR}=68.3 \%$ at the ratio of $\mathrm{MgCO}_{3}$ and AZC (w/w) was 2:1 (the SDR data are shown in Table 1).

Tab. 2. TG-DTG-DTA results of the PVC samples.

\begin{tabular}{|c|c|c|c|c|c|c|c|c|c|}
\hline \multirow[b]{2}{*}{ sample } & \multirow[b]{2}{*}{$\begin{array}{l}\mathrm{TE} \\
{\left[{ }^{\circ} \mathrm{C}\right]}\end{array}$} & \multicolumn{4}{|c|}{ The first stage } & \multicolumn{4}{|c|}{ The second stage } \\
\hline & & $\begin{array}{c}\mathrm{T} \\
\text { range } \\
{\left[{ }^{\circ} \mathrm{C}\right]}\end{array}$ & $\begin{array}{c}\text { Weight } \\
\text { loss } \\
{[\%]}\end{array}$ & $\begin{array}{c}\mathrm{MV} \\
{\left[\mathrm{mg} \cdot \mathrm{min}^{-1}\right]}\end{array}$ & $\begin{array}{l}\mathrm{TM} \\
{\left[{ }^{\circ} \mathrm{C}\right]}\end{array}$ & $\begin{array}{c}\mathrm{T} \\
\text { range } \\
{\left[{ }^{\circ} \mathrm{C}\right]}\end{array}$ & $\begin{array}{c}\text { Weight } \\
\text { loss } \\
{[\%]}\end{array}$ & $\begin{array}{c}\mathrm{MV} \\
{\left[\mathrm{mg} \cdot \mathrm{min}^{-1}\right]}\end{array}$ & $\begin{array}{l}\mathrm{TM} \\
{\left[{ }^{\circ} \mathrm{C}\right]}\end{array}$ \\
\hline a & 541 & $\begin{array}{l}244- \\
350\end{array}$ & 67.1 & 1.43 & 297 & $\begin{array}{c}437- \\
617\end{array}$ & 29.2 & 0.36 & 539 \\
\hline b & 540 & $\begin{array}{c}248- \\
350\end{array}$ & 51.4 & 2.09 & 297 & $\begin{array}{c}436- \\
609\end{array}$ & 27.0 & 0.56 & 516 \\
\hline C & 567 & $\begin{array}{c}236- \\
275\end{array}$ & 50.4 & 6.76 & 247 & $\begin{array}{c}410- \\
616\end{array}$ & 34.3 & 0.68 & 548 \\
\hline$d$ & 548 & $\begin{array}{c}236- \\
311\end{array}$ & 50.4 & 2.32 & 241 & $\begin{array}{c}424- \\
591\end{array}$ & 29.5 & 0.49 & 487 \\
\hline
\end{tabular}

As shown in Figure 1 and Table 2, the DTA curves of all PVC samples had an exothermic peak at about $550^{\circ} \mathrm{C}$, which corresponds to the oxidation of the unstable char. The DTA curve of the PVC sample treated with $\mathrm{MgCO}_{3}$ (Figure $1(\mathrm{~b})$ ) is similar to that of the untreated PVC sample (Figure 1(a)). Incorporation of $\mathrm{MgCO}_{3}$ thus did not have much effect on the DTA curve of the PVC. However, the DTA curve of the sample treated with AZC is significantly different from that of the untreated PVC. The exothermic peak becomes very sharp, the exothermic peak temperature (TE) is obviously increased and there is a small endothermic peak which appears at about $260{ }^{\circ} \mathrm{C}$, corresponding with the endothermic decomposition of AZC (Figure 2(b)). For the sample treated with $\mathrm{MgCO}_{3}$ and $\mathrm{AZC}$, there is a small endothermic peak at about $260{ }^{\circ} \mathrm{C}$ also; the exothermic peak is divided into two small peaks at 490 and $550{ }^{\circ} \mathrm{C}$ (Figure 1(d)), which mean that the structure of char residue was changed. 
For further understanding of the flame retardant effect on PVC degradation process, we calculated the new curves by linear combination of the TG curves of untreated PVC and the three different flame retardants respectively, according to the proportion of flame retardant in plasticized PVC. And the specific results are showed in Figure 3.
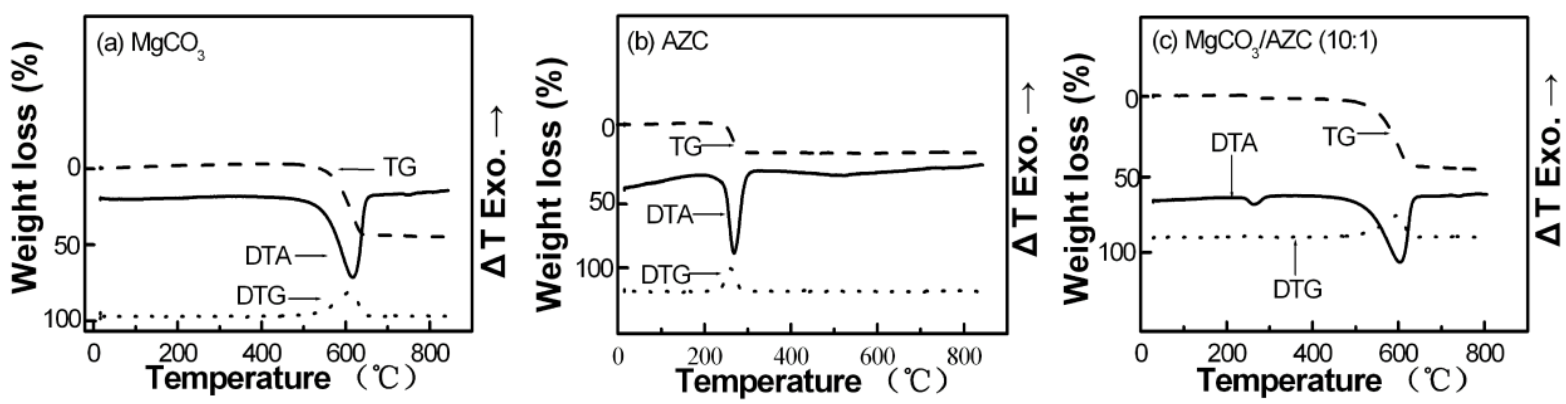

Fig. 2. TG-DTA-DTG curves of the flame retardants. (Samples were heated at a rate of $20{ }^{\circ} \mathrm{C} \mathrm{min}-1$ under air with a flow rate of $60 \mathrm{ml} \mathrm{min}^{-1}$ ).

In Figure 3(a), in the first stage, the experimental curve (TG curve) of the $\mathrm{MgCO}_{3}$ treated sample is very similar with the calculated curve and the untreated PVC curve, while in the second stage the weight loss of the experimental results are obviously smaller than the calculated results, which mean that $\mathrm{MgCO}_{3}$ mainly affect the thermal degradation of PVC in the second stage. These results correspond with the thermal decomposition of $\mathrm{MgCO}_{3}$ (Figure 2 (a)).
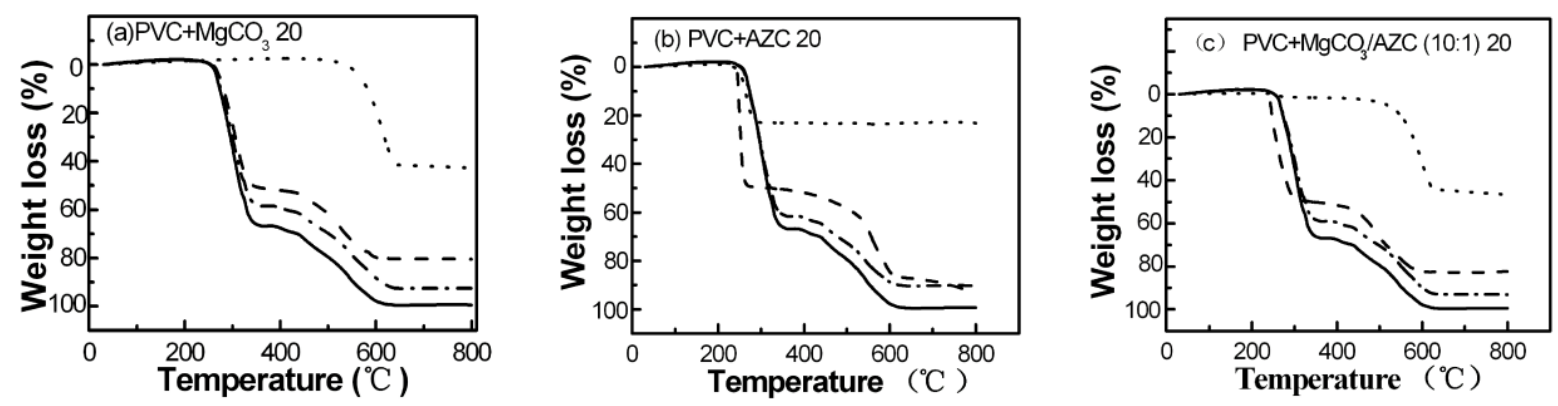

Fig. 3. TG curves of the samples. (Samples were heated at a rate of $20{ }^{\circ} \mathrm{C} \mathrm{min}^{-1}$ under air with a flow rate of $60 \mathrm{ml} \mathrm{min}^{-1}$ ) (a) $\mathrm{PVC}_{+} \mathrm{MgCO}_{3} 20 \mathrm{phr}$; (b) PVC+AZC 20 phr; (c) $\mathrm{PVC}+\mathrm{MgCO}_{3} / \mathrm{AZC}(10: 1) 20$ phr, PVC curve (-), flame retardants curve $(\cdots \cdots)$, experimental curve $(--)$, calculated curve $(---)$.

In Figure 3 (b), at the first stage, the main character of the experimental curve (TG curve) of the AZC-treated sample is that the initial decomposition temperature is decreased and the weight loss rate is increased clearly. These results can be explained with the assumption of that $A Z C$ decomposed at about $220{ }^{\circ} \mathrm{C}$ (Figure 2 (b)) and form $\mathrm{ZnO}$, which can react with $\mathrm{HCl}$ and form $\mathrm{ZnCl}_{2}$, and then catalyze the dehydrochlorination and promote the early crosslinking to the PVC compound, so the char residue of the experimental results are higher than the calculated results from 220 to $600{ }^{\circ} \mathrm{C}$, while after $600{ }^{\circ} \mathrm{C}$ the experimental curve and calculated curve are very close, especially after $700{ }^{\circ} \mathrm{C}$, with the experimental curve a little lower than the calculated curve; these results show that the AZC will promote the further degradation reactions of the char residue at high temperature. In Figure 3 (c), when PVC sample treated with the composites of $\mathrm{MgCO}_{3}$ and $\mathrm{AZC}$, the flame retardants 
cannot only decrease the initial decomposition temperature and increase the weight loss rate in the first stage but also can promote the char formation in the second stage. So $\mathrm{MgCO}_{3}$ and AZC have a synergistic effect as flame retardants and smoke suppressants for flexible PVC.

\section{Kinetic study}

We calculated the activation energies for the polymer degradation, with and without flame retardant, using dynamic integral TG curves at various heating rates, as proposed by Vyazovkin $[18,19]$. The equation is as follows:

$\ln \frac{\beta}{T_{\alpha}^{2}}=\ln \left[\frac{R k_{0}}{E_{\alpha} g(\alpha)}\right]-\frac{E_{\alpha}}{R} \frac{1}{T_{\alpha}}$

Where $\beta$ is the heating rate in $\mathrm{K} \cdot \mathrm{min}^{-1}(\beta=5,10,15,20), \alpha$ is the conversion, $T_{\alpha}$ the temperature at conversion $\alpha$ with various heating rates, $g(\alpha)$ is a function of the reaction rate equation, $k_{0}$ is the frequency factor of the Arrhenius Equation, $R$ is the gas constant $\left(8.314 \mathrm{~J} \cdot \mathrm{K}^{-1} \cdot \mathrm{mol}^{-1}\right)$, and $E_{\alpha}$ is the $E_{\mathrm{a}}$ at conversion $\alpha$.

The chemical reaction was measured at least at three different heating rates $(\beta)$ and the respective conversion curves were calculated out of the TG curves. For each conversion $\alpha, \ln \left(\beta / T_{\alpha}^{2}\right)$ was plotted versus $1 / T_{\alpha}$, giving a straight line with the slope $-E_{\alpha} / R$, and therefore the $E_{\mathrm{a}}$ could be obtained as a function of conversion. This is defined as a dynamic equation, and it was used for the determination of the $E_{\mathrm{a}}$ for all conversion values (Figure 4).

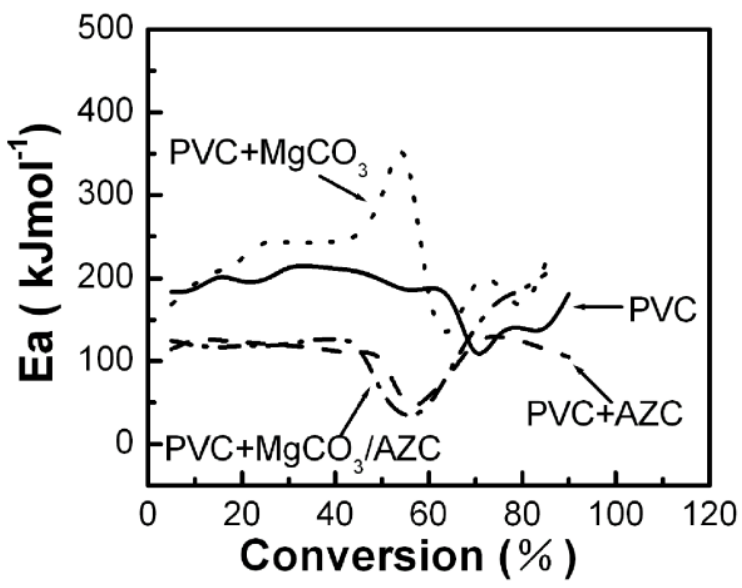

Fig. 4. Activation energy vs. conversion for PVC samples thermal degradation in air.

It can be observed that the untreated PVC and the flame retardant PVC sample exhibited different $E_{\mathrm{a}}$ curve profiles. As shown in Figure 4, the $E_{\mathrm{a}}$ of the untreated PVC sample increased at the beginning of PVC degradation process and then decreased with the highest value of $E_{\mathrm{a}}=210 \mathrm{~kJ} \cdot \mathrm{mol}^{-1}$ at the conversion was $30 \%$. Then it decreased and stabilized at about $190 \mathrm{~kJ} \cdot \mathrm{mol}^{-1}$ up to $65 \%$; the $E_{\mathrm{a}}$ further decreased sharply with a minimum value of about $130 \mathrm{~kJ} \cdot \mathrm{mol}^{-1}$ at the conversion was $85 \%$, which corresponds with the oxidation of the unstable char in the second degradation stage. At even higher conversions, the value of $E_{\mathrm{a}}$ increased. The $E_{\mathrm{a}}$ of the $\mathrm{MgCO}_{3}$-treated sample is higher than that of the untreated PVC sample, and with the highest value of $E_{\mathrm{a}}=360 \mathrm{~kJ} \cdot \mathrm{mol}^{-1}$ at the conversion was $55 \%$, which is related to 
the endothermic degradation of $\mathrm{MgCO}_{3}$ at $500{ }^{\circ} \mathrm{C}$ (see Figure 2 (a)), then decrease and the minimum value reaches $130 \mathrm{~kJ} \cdot \mathrm{mol}^{-1}$ when the conversion was $65 \%$, but the $E_{\mathrm{a}}$ of the oxidation reaction of the char is higher than the untreated PVC sample. The $E_{\mathrm{a}}$ of the AZC-treated sample is lower than that of the untreated PVC sample at all the stages, while with presence of the composite of $\mathrm{MgCO}_{3}$ and $\mathrm{AZC}(10: 1)$, the result shows that the $E_{\mathrm{a}}$ of the sample is lower than the untreated PVC sample at low convertion $(<65 \%)$ and higher at high convertion ( $>65 \%)$. So the composite of $\mathrm{MgCO}_{3}$ and $\mathrm{AZC}(10: 1)$ both can catalyze the dehydrochlorination, promote the early crosslinking of the PVC compound and can improve the stability of the char.

\section{SEM of the char}

The surface morphology of the char residue after SDR test was investigated with SEM, and the images are shown in Figure 5. It can be seen in Figure 5(a), (d) that the formed from $\mathrm{MgCO}_{3}$ treated PVC sample shows a compact structure with small pores and the char is brittle, as the magnification increases, there are some small white particles which can be recognized in the char surface, which should be $\mathrm{MgO}$ generated from decomposition of $\mathrm{MgCO}_{3}$. The char formed in $\mathrm{AZC}$-treated sample shows a fusing structure, the char looked soft and there are no obvious particles distributed on the surface; whereas the char formed in $\mathrm{MgCO}_{3} / \mathrm{AZC}$ treated sample shows a continuous and dense structure which can be used as a barrier to inhibit the volatilization of combustible gases and the transfer of heat energy to the PVC bulk, which is beneficial to the improvement of flame retardancy.

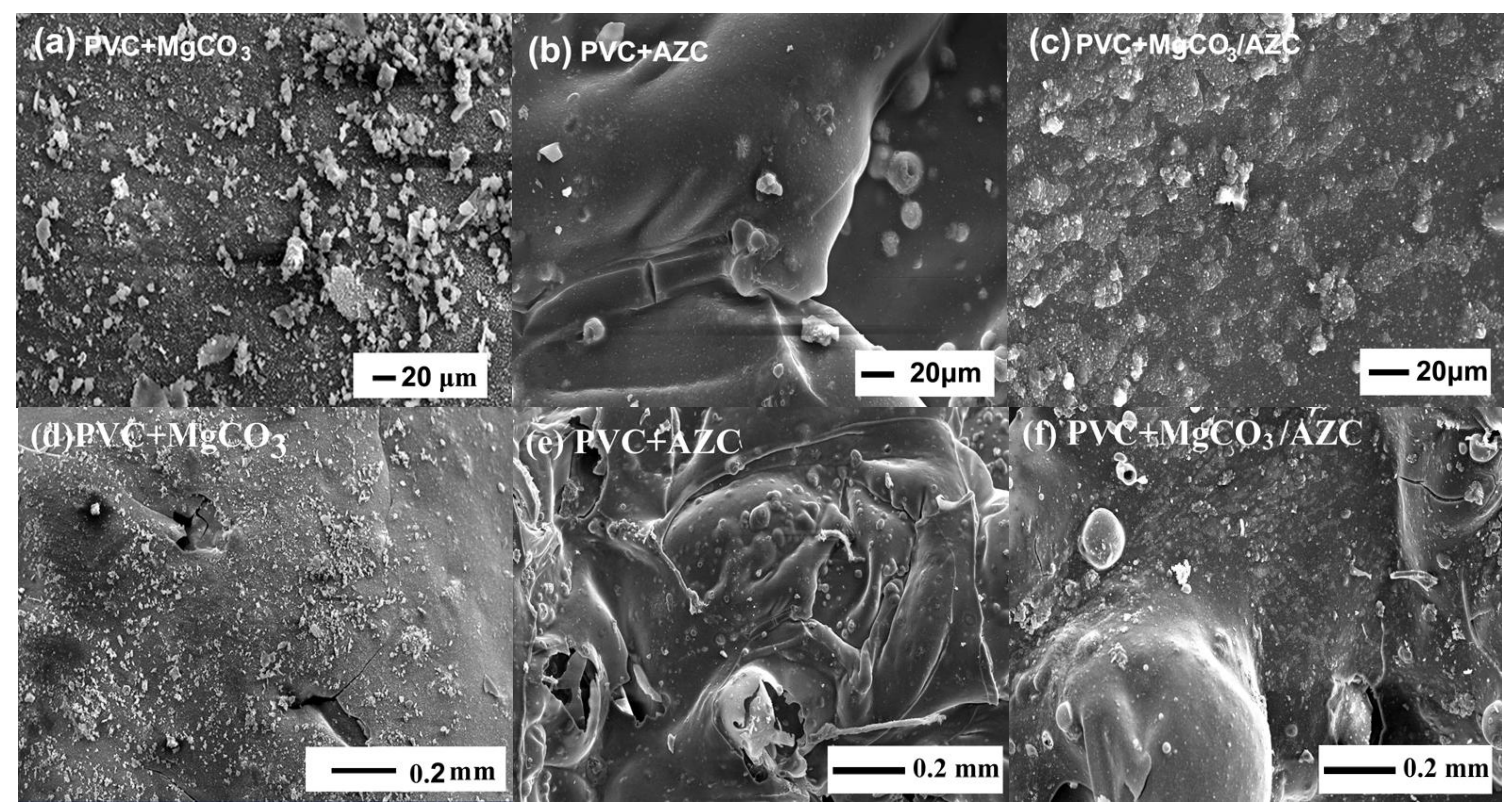

Fig. 5. SEM of the char formed after combustion of the PVC samples. (a),(d) PVC+MgCO 20 phr; (b), (e) PVC+AZC 20 phr; (c), (f) PVC+MgCO $3 / A Z C ~(10: 1) 20$ phr.

\section{Conclusions}

The flame retardancy of flexible PVC treated with $\mathrm{MgCO}_{3}$ and $\mathrm{AZC}$ were studied by $\mathrm{LOI}$ and SDR, and a synergistic behavior for the mixture of $\mathrm{MgCO}_{3}$ and $\mathrm{AZC}$ was found. The decomposition of the different PVC samples has been characterized by the TGA. The results showed that a small proportion of AZC can obviously decrease 
the initial decomposition temperature and the TM of the sample, and increase the $\mathrm{MV}$, in the first stage. Corresponding with the thermal decomposition of $\mathrm{MgCO}_{3}$, it mainly affects the thermal degradation of PVC in the second stage, and it can obviously increase the yield and improve the stability of the char residue.

The AZC can decrease the $E_{\mathrm{a}}$ of the degradation reaction of $\mathrm{PVC}$, while $\mathrm{MgCO}_{3}$ can obviously increase the $E_{\mathrm{a}}$ of the degradation reaction, and the maximum value is at about $55 \%$, which is related to the endothermic degradation of $\mathrm{MgCO}_{3}$. The $E_{\mathrm{a}}$ can be significantly decreased by a small amount of AZC combined with $\mathrm{MgCO}_{3}$ which as flame retardants for flexible PVC in the first degradation stage, while in the second stage, the $E_{\mathrm{a}}$ has been increased obviously.

The char formed in PVC treated with the composites of $\mathrm{MgCO}_{3}$ and $\mathrm{AZC}$ has a continuous and dense structure which can be used as a barrier to inhibit the volatilization of combustible gases and the transfer of heat energy to the PVC bulk, which is beneficial to the improvement of flame retardancy.

The synergism mainly due to that a small amount of $\mathrm{AZC}$ can decompose to $\mathrm{ZnO}$, and $\mathrm{ZnO}$ can be further reacted with $\mathrm{HCl}$ and form $\mathrm{ZnCl}_{2}, \mathrm{ZnCl}_{2}$ can catalyze the dehydrochlorination and promote the early crosslinking of the PVC compound in the first stage; and $\mathrm{MgCO}_{3}$ can increase the stability of the char residue in the second stage.

\section{Experimental}

\section{Materials}

PVC TL-1000 (Beijing the Second Chemicals Co., Beijing, China) was used as the polymer matrix, DOP was used as the plasticizer (Shanghai Dongfang Chemicals Co., China), organic tin compound was used as stabilizer and calcium stearate was used as lubricant (Baoding Chemicals Co., Baoding, China), $\mathrm{MgCO}_{3}$ and $\mathrm{AZC}$ $\left(2 \mathrm{ZnCO} \cdot 3 \mathrm{ZnO} \cdot 4 \mathrm{H}_{2} \mathrm{O}\right)($ Tianjin Chemicals Co., Tianjin, China) were used as the flame retardants.

\section{Preparation of the PVC Samples}

Samples were prepared by mixing PVC with DOP, heat stabilizer, lubricant, coupling agent (NDZ-311, Bis(P,P-bis-ethylhexyl diphosphato)ethanediolato titanate)), and a certain content of flame retardants. The blending process was carried out in a two roll mill at $170{ }^{\circ} \mathrm{C}$ for 10 minutes and then the samples were compressed at $180{ }^{\circ} \mathrm{C}$ and $15 \mathrm{MPa}$ to form sheets of $140 \mathrm{~mm} \times 50 \mathrm{~mm} \times 3 \mathrm{~mm}$. The test specimens were cut from the molded sheets. The basic recipe of the sample is: PVC $100 \mathrm{phr}$, DOP 40 phr, stabilizer $3 \mathrm{phr}$, calcium stearate $1 \mathrm{phr}$, coupling agent $1 \mathrm{phr}$, and flame retardants $20 \mathrm{phr}$.

\section{Measurements and Characterization}

The LOI is the minimum percentage oxygen for maintaining specimen's flaming combustion under specified laboratory conditions. LOI values were determined with General Model HC-2 LOI instrument (Nanjing Jiangning Analysis Instrument Factory, Nanjing, China) according to ASTM D2863-2000. The dimension of the sample was 3 $\mathrm{mm} \times 6 \mathrm{~mm} \times 140 \mathrm{~mm}( \pm 0.1 \mathrm{~mm})$. 
The SDR values and the maximum of smoke density (MSD) values were determined in accordance with ASTM D 2843-1993 by means of a General Model JCY-1 instrument (Nanjing Jiangning Analysis Instrument Factory, Nanjing, China).

Thermal degradation of the samples were determined by TGA, differential thermogravimetry analysis (DTG) and differential thermal analysis (DTA). The analyses were carried out on a WCT-2 (Beijing optical instrument Co. Ltd., China) thermoanalytical apparatus. $7 \pm 0.2 \mathrm{mg}$ samples (platinum pan) were heated from ambient temperature to $800^{\circ} \mathrm{C}$ at a heating rate of $5,10,15,20^{\circ} \mathrm{C} \cdot \mathrm{min}^{-1}$ under an air flow rate of $60 \mathrm{ml} \cdot \mathrm{min}^{-1}$. To ensure the accuracy of the data, three parallel experiments were conducted.

The morphology of the char formed after combustion of the samples was investigated by SEM (SEM-AMARRY-1000B-2, Chinese Academic of Science Instrument Factory, Beijing, China). Before observation, the surfaces of the char were covered with gold.

\section{Acknowledgements}

The authors gratefully acknowledge the financial support by the Natural Science Fund of Hebei Province (China No. B2007000144) and the science and technology study direction plan of Baoding city (China No. 09ZF020).

\section{References}

[1] Rothon, R. N.; Hornsby, P. R. Polym. Degrad. Stab. 1996, 54, 383.

[2] Hornsby, P. R.; Watson, C. L. Polym. Degrad. Stab. 1990, 30, 73.

[3] Ning, Y.; Guo, S. Y. J. Appl. Polym. Sci. 2000, 77, 3119.

[4] Pi, H.; Guo, S. Y.; Ning, Y. J. Appl. Polym. Sci. 2002, 89, 753.

[5] Rigolo, M.; Woodhams, R. T. Poly. Eng. Sci. 1992, 32, 327.

[6] Du, G.X.; Hao, D.; Bai, K. W.; Xue, Q. Materials Science Forum 2009, 610 - 613, 165.

[7] Bertalan, G. Y.; Marosi, G. Y. Solid State lonics 2001, 141-142, 211.

[8] Hejazy, E. S. A.; Seguchi, T.; Machi, S. J. Appl. Polym. Sci. 1981, 26, 2947.

[9] Cross, M. S.; Cusack, P. A.; Hornsby, P. R. Polym. Degrad. Stab. 2003, 79, 309.

[10] Tian, C. M.; Qu, H. Q.; Wu, W. H.; Guo, H. Z.; Xu, J. Z. J. Vinyl. Addit. Technol., 2005, 11 (2), 70.

[11] Tian, C. M.; Qu, H. Q.; Wu, W. H.; Guo, H. Z.; Xu, J. Z. J. Fire. Sci. 2004, $22,41$.

[12] Qu, H. Q.; Wu, W. H.; Jiao, Y. H.; Xu, J. Z. Polym. Int. 2005, 54(11), 1469.

[13] Levchik, S. V.; Weil, E. D. Polym. Adv. Technol. 2005, 16, 707.

[14] Tian, C. M.; Wang, H.; Liu, X. L.; Xu, J. Z. J. Appl. Polym. Sci. 2003, 89, 3137.

[15] Gumargalieva, K. Z.; Ivanov, V. B.; Zaikov, G. E.; Moiseev, J. V.; Pokholok, T. V. Polym. Degrad. Stab. 1996, 52, 73.

[16] Manzoor, W.; Yousaf, S. M.; Ahmad, Z. Polym. Degrad. Stab. 1996, 51, 295.

[17] Willianm, J. K. J. Appl. Polym. Sci. 1981, 26, 1167.

[18] Fernandes, V. J.; Araujo A. S.; Fonseca V. M. Thermochim. Acta. 2002, 392$393,71$.

[19] Vyazovkin, S.; Wight, C. A. Thermochim. Acta. 1999, 340-341, 53. 